\title{
The diagnostic value of ultrasound in cystic kidney diseases
}

\author{
Udo Vester • Birgitta Kranz $\cdot$ Peter F. Hoyer
}

Received: 29 May 2008 /Revised: 4 August 2008 / Accepted: 5 August 2008 / Published online: 23 September 2008

(C) IPNA 2008

\begin{abstract}
Renal cysts in childhood can be found in a variety of diseases, which can be congenital or acquired, or renal cysts may be part of a multiorgan disease or restricted to the kidneys only. Ultrasonography is the first-line diagnostic tool and is informative in many cases. However, there is a broad spectrum in the sonographic appearance of renal cysts, and family or genetic studies, a search for extrarenal organ involvement, or additional imaging modalities may be required to make a definitive diagnosis. The aim of this article is to summarize the diagnostic potential and limitations of ultrasonography and depict typical examples of the most important cystic entities.
\end{abstract}

Keywords Renal cysts · Cystic kidney disease · Ultrasound · Children · Diagnosis

\section{Introduction}

Cysts are defined as spherical, fluid-filled, thin-walled structures that may be single or multiple. With the widespread availability of ultrasound, renal cysts in children can be diagnosed during the mother's pregnancy or early childhood. There is no universally accepted classification for renal cysts, and according to a recent textbook: "it appears likely that cystic diseases of the kidney will be repeatedly reclassified with future insights into their pathogenesis" [1]. We have followed a proposal

U. Vester $(\triangle) \cdot$ B. Kranz $\cdot$ P. F. Hoyer

Children's Hospital, University of Duisburg-Essen,

Hufelandstr. 55,

45122 Essen, Germany

e-mail: udo.vester@uk-essen.de to classify developmental disorders of the kidneys to different stages of nephrogenesis [2], as follows:.

Renal cystic diseases classified to the time they develop in relation to the stage of nephrogenesis

1. Before nephrogenesis:

Multicystic dysplasia

2. Early during nephrogenesis:

Dysplastic kidney with cysts

- Isolated

- As part of syndromes

- With obstruction

3. After nephrogenesis:

Systemic cystic renal diseases

- Autosomal recessive

- Autosomal dominant

- Nephronophthisis

- Medullary cystic disease

4. Miscellaneous:

- Isolated cysts

- Acquired renal cysts

- Cysts within tumors

- Metabolic diseases

It is the aim of this paper to summarize the technical requirements and sonographic images of renal cystic diseases and give examples of entities that should be familiar to the pediatric nephrologist.

\section{Technical requirements}

Ultrasound fulfills the requirements of an ideal diagnostic tool in childhood: it does not expose the patient to 
radiation or contrast media, it can be repeated easily, it does not need patient preconditioning, and it offers good sensitivity and specificity. In addition, ultrasound allows family screening when indicated, with the same advantages. However, standardized and continuous operator training is essential, as it may reduce the "operator dependency" of ultrasound.

The kidneys can be visualized from both sides in a supine position. In older patients, the examination is mostly completed from the back with the patient in the prone position. Because of the well-defined interface to the surrounding tissue, ultrasound identification of cysts allows their visualization down to a size of $1 \mathrm{~mm}$.

Modern ultrasound equipment should include probes suitable to depict the spectrum of renal diseases through the whole pediatric age range. This requires a sector probe and a linear probe of at least $8 \mathrm{MHz}$ for infants and a $4-\mathrm{MHz}$ sector probe for adolescents. Cysts in the kidneys are usually identified with the B-mode scan only, but modern technical facilities such as Doppler or harmonic mode may allow easier orientation or increase sensitivity.

It is important to emphasize that ultrasound in children with renal cysts should not be restricted to the kidneys, because multiorgan involvement in systemic cystic disease or syndromes should always be anticipated and included in the diagnostic workup.

Other imaging modalities may add additional information, such as magnetic resonance imaging (MRI) in extrarenal organ involvement or within interventional studies [3, 4]; radiological studies may help depict urological pathologies, such as vesicoureteral reflux; and scintigraphy helps measure renal function [5]. The growing knowledge of the genetic basis of cystic kidney diseases allows identification of hereditary origin [6].

\section{Renal cystic diseases}

Multicystic renal dysplasia. Multicystic renal dysplasia or multicystic dysplastic kidney is the most common cystic malformation of the kidney among infants. It is found in approximately 1 in 4,000 live births [7]. On ultrasound, the multicystic kidney typically consists of several variablesized cysts without identifiable renal parenchyma between these cysts (Fig. 1a,b). The ureter is atretic in most cases, and the multicystic kidney does not show residual function. Bilateral disease is fatal in the newborn period, but usually only one kidney is affected. Most cases of multicystic renal dysplasia are suspected during prenatal ultrasound examination and should be followed after birth. Ultrasound often allows differentiation from severe hydronephrosis. However, in doubtful cases, scintigraphy to detect residual function or drainage may be indicated [5]. As involution of the multicystic dysplastic kidney is frequently observed [8], which can be followed sonographically, routine nephrectomy is not recommended and is reserved for some cases with hypertension or malignant transformation (Fig. 1c), or cases with an exceptionally large cystic kidney

Fig. 1 Multicystic dysplasia: a macroscopic appearance; b typical example of sonographic appearance; c multicystic kidney with nephroblastoma (marked with calipers); d giant-size multicystic kidney (approximately 900-ml volume) in a 2-year-old girl, crossing the midline (transverse section, * vertebral column)
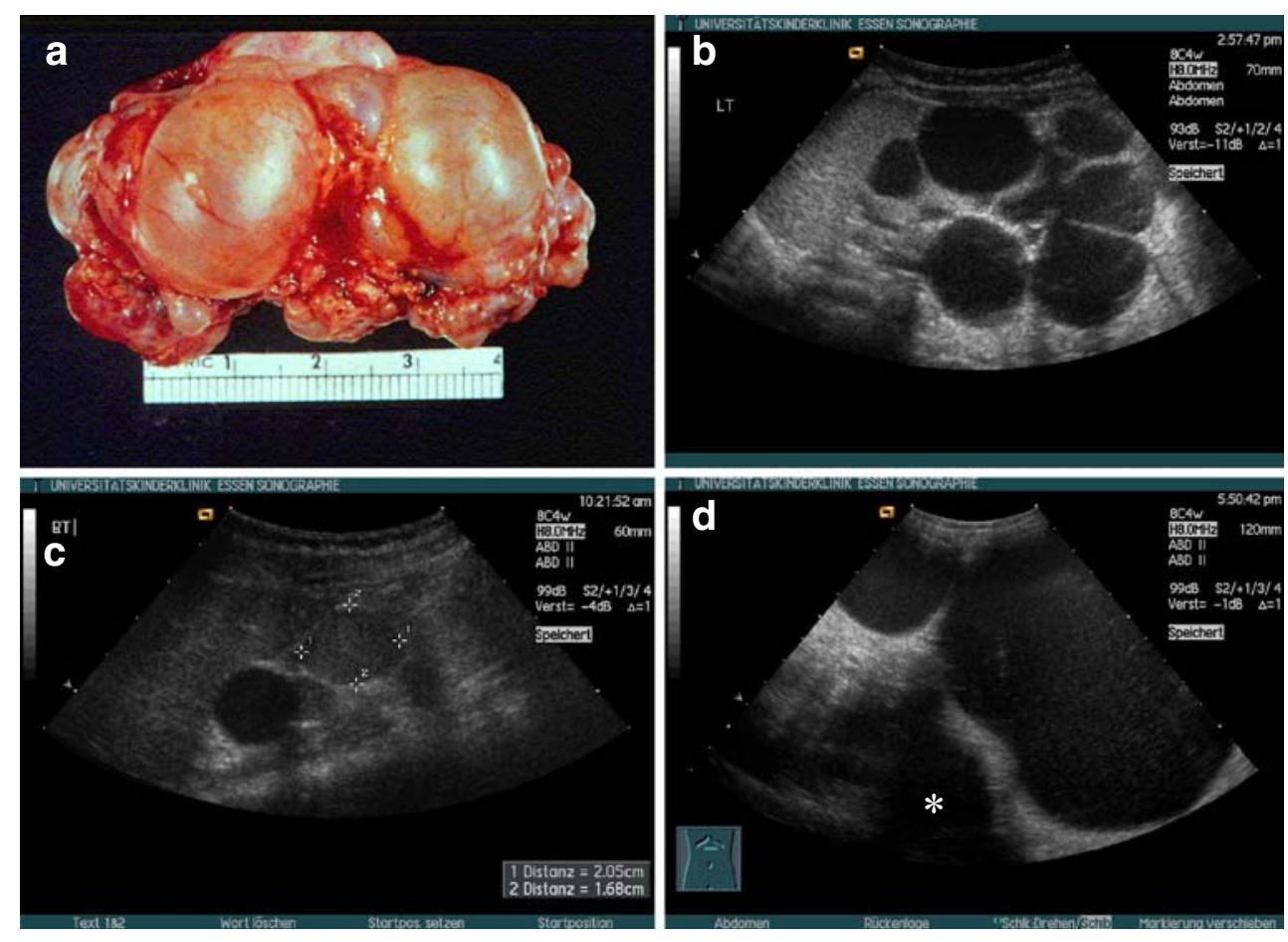
Fig. 2 Renal dysplasia with cysts: a dysplastic kidney with a single and small cyst (13-yearold boy, creatinine $2.0 \mathrm{mg} / \mathrm{dl}) ; \mathbf{b}$ dysplastic kidney with numerous cysts (2-week-old boy, endstage renal failure within first year of life); $\mathbf{c}, \mathbf{d}$ dysplastic kidneys with cysts and different function (c 6-year-old patient, creatinine $0.64 \mathrm{mg} / \mathrm{dl}$; d 5 -weekold patient, creatinine $2.0 \mathrm{mg} / \mathrm{dl}$, end-stage renal failure at 6 months)
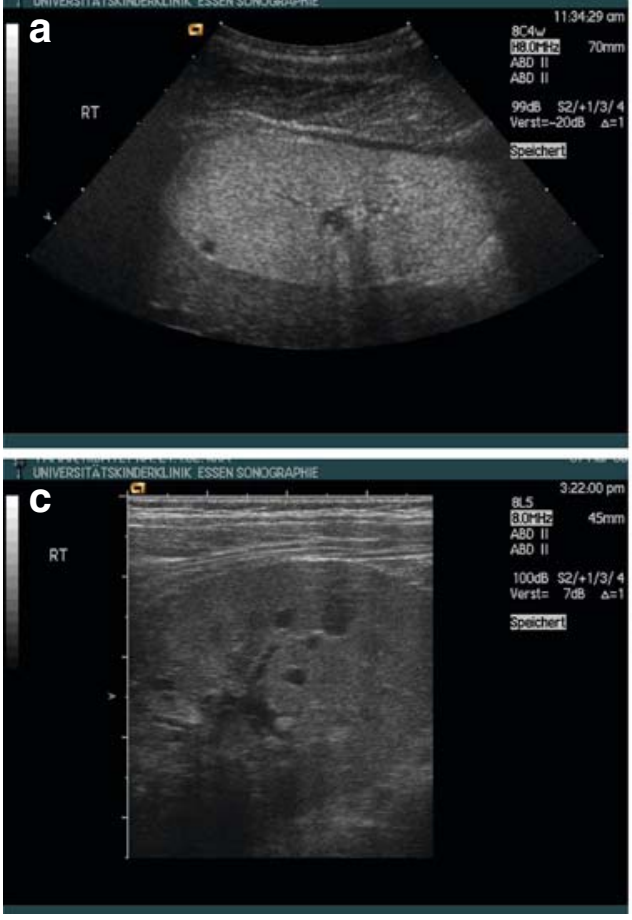
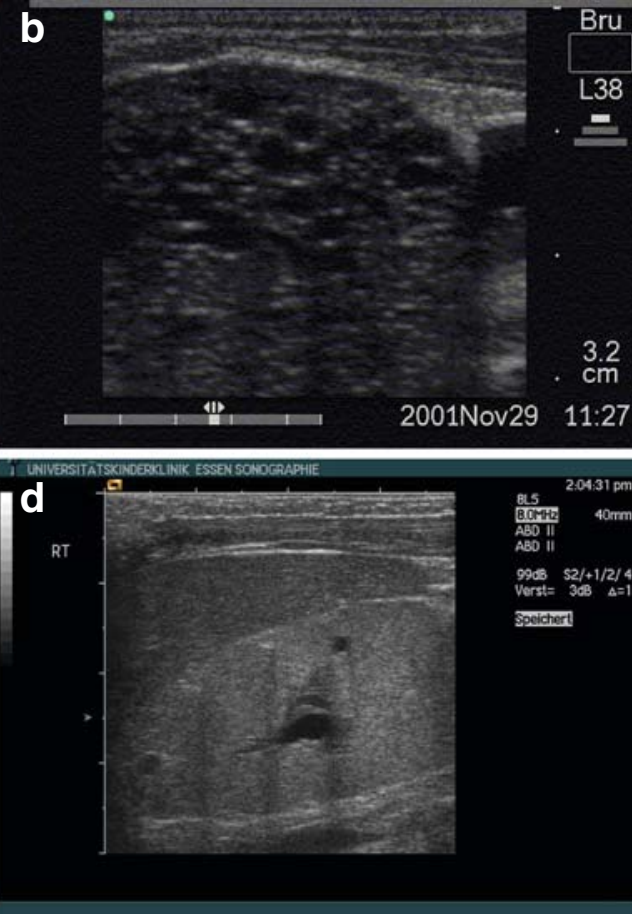

(Fig. 1d). As even after sonographic involution a remnant of the multicystic kidney can be expected, long-term follow-up seems advisable [9].

The contralateral kidney should receive special attention, as this kidney should hypertrophy to guarantee normal renal function and has been shown to have an increased incidence $(20-40 \%)$ of minor malformations, such as vesicoureteral reflux [10-12]. Usually, multicystic dysplastic kidney is an incidental finding, but familial occurrence has been described [13].

Renal dysplasia with cysts. Renal dysplasia is a histological entity with undifferentiated parenchyma with or
Fig. 3 Phenotypic variability of renal dysplasia and cysts in a family with three siblings and hepatocyte nuclear factor (HNF) $1 \beta$-mutation (mother has renal cysts, creatinine of $1.5 \mathrm{mg} / \mathrm{dl}$ and uterus bicornis): a, b index case (boy, end-stage renal failure within 10 months) (a multicystic dysplasia on the right side; $\mathbf{b}$ dysplasia without cysts on the left side); c sister, creatinine $1.0 . \mathrm{mg} / \mathrm{dl}$ at the age of 1 year, dysplasia with cysts; d intrauterine enlarged kidneys in a third child, resembling autosomal recessive polycystic kidney disease (ARPKD)
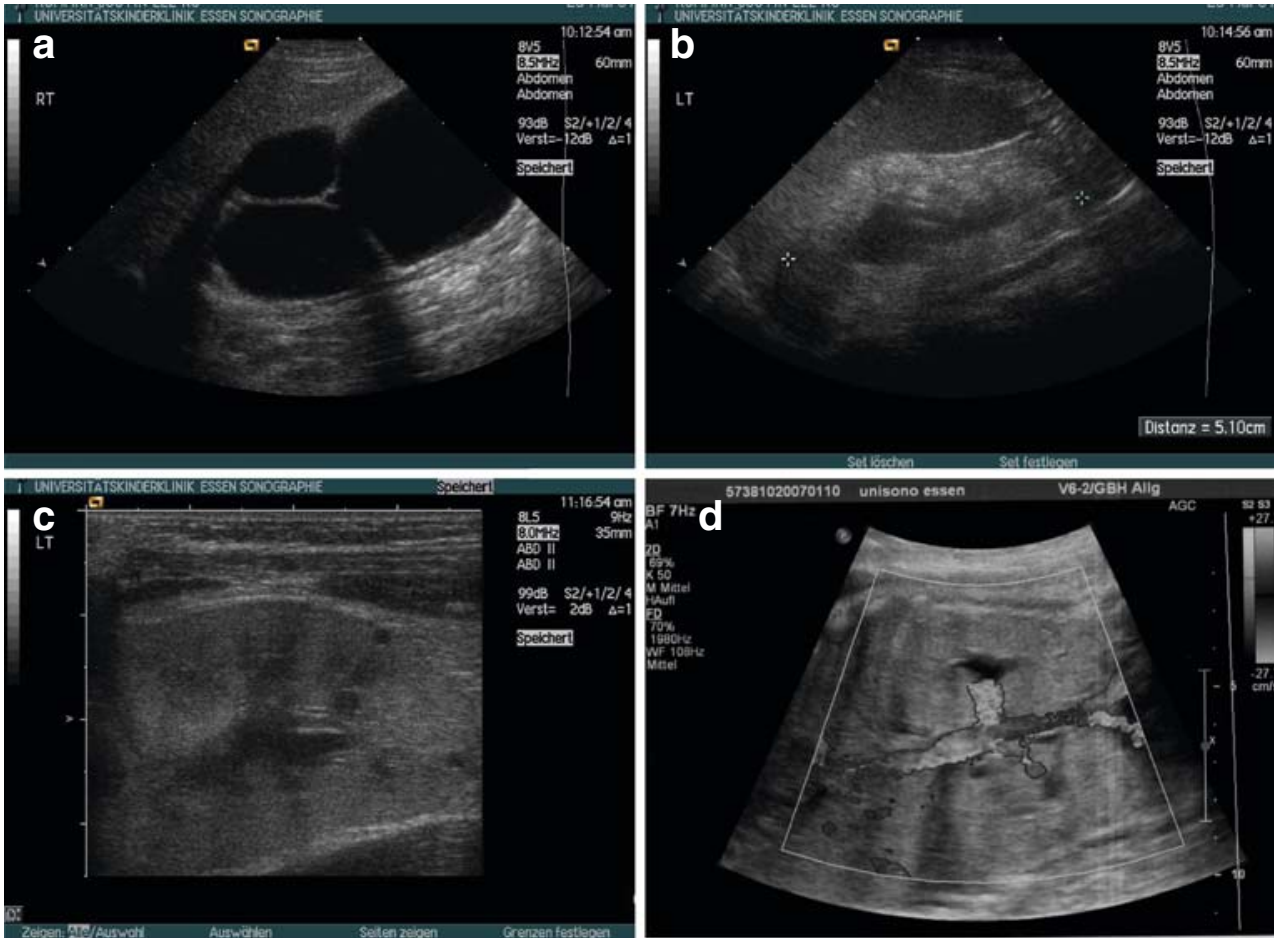
Fig. 4 Renal dysplasia with cysts and urinary tract dilation (CAKUT congenital anomalies of kidney and urinary tract): $\mathbf{a}, \mathbf{b}$ boy with urethral valves and impaired renal function (creatinine $1.5 \mathrm{mg} / \mathrm{dl}$ ) at the age of 6 weeks (a dilated ureters and thickened bladder wall, b dysplastic right kidney with small cysts); c girl with duplex collecting system: the small upper kidney pole shows cystic dysplasia and the lower pole normal parenchyma; $\mathbf{d}$ upper kidney pole in a duplex collecting system, with lack of corticomedullary differentiation in the upper pole, indicating dysplasia without cysts
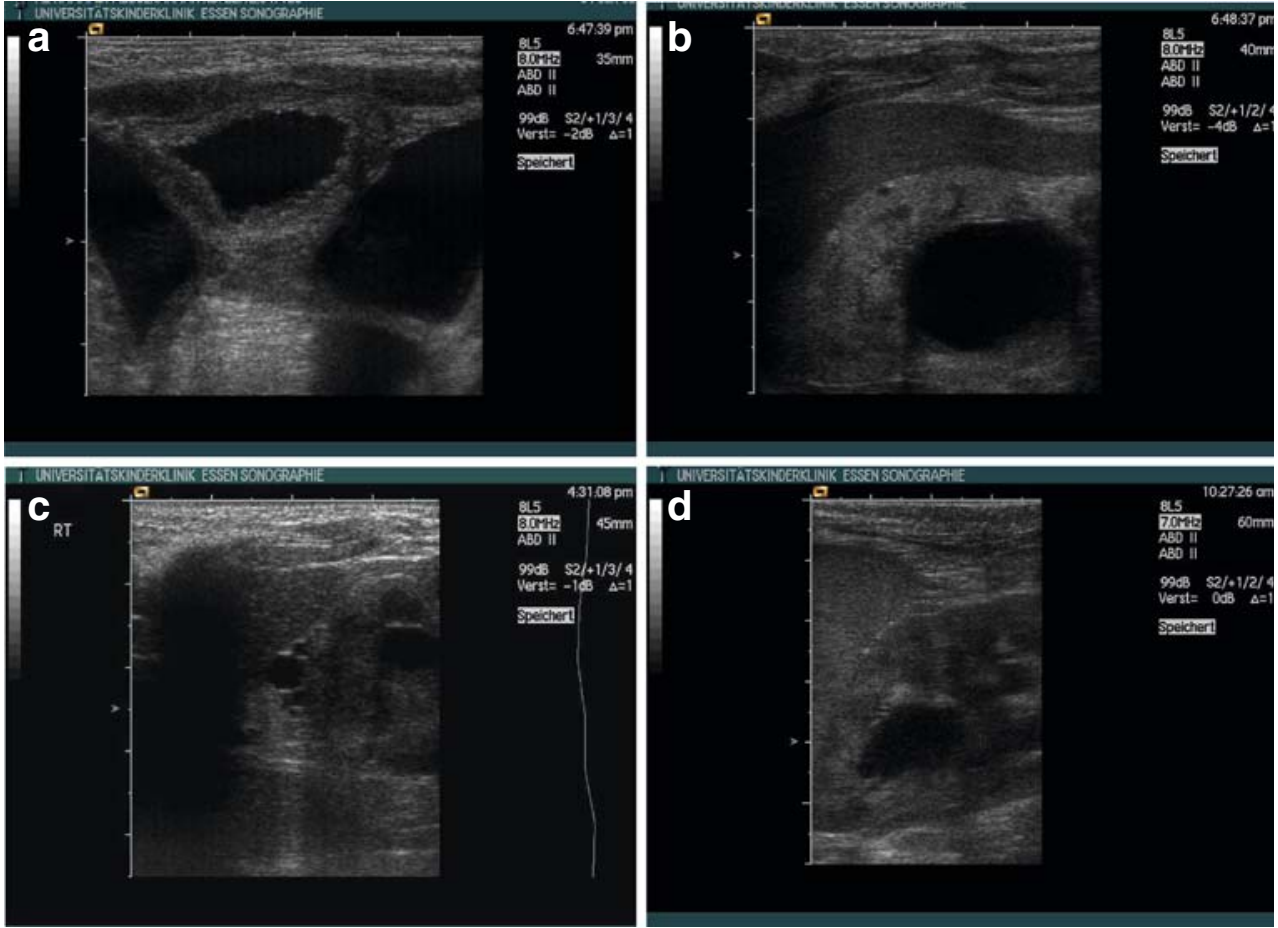

without cysts. Renal histology is characterized by poorly differentiated glomeruli, atypical tubuli, or nonrenal-tissuelike cartilage [14]. Renal dysplasia can affect one or both kidneys or may be segmental in some cases. Renal function of the affected kidney is more or less reduced; in bilateral cases, progressive loss of function may lead to renal failure. In large series, renal dysplasia is one of the leading causes of end-stage renal failure in childhood [15]. Therefore, monitoring renal function is more important than repeated ultrasound examinations.
Fig. 5 Autosomal recessive polycystic kidney disease (ARPKD) in neonates: a 2week-old boy with typical echogenic spots representing small cysts; b 2-week-old girl with subcapsular brush-like appearance of dilated collecting ducts; c girl with giant-sized kidneys and ARPKD; d same patient as in c: transverse abdominal section with enlarged kidneys touching in the midline (* vertebral column)
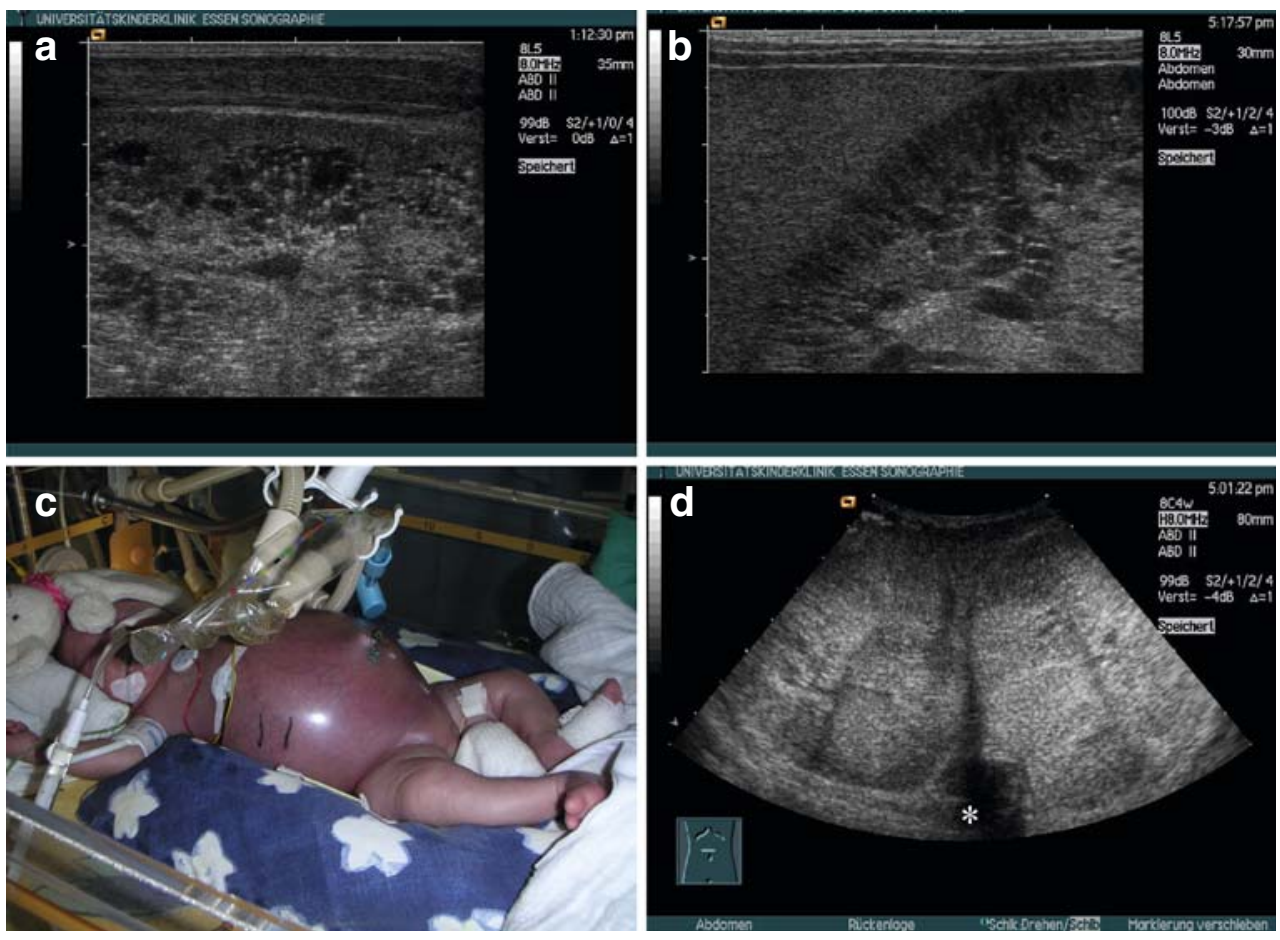
Fig. 6 Autosomal recessive polycystic kidney disease (ARPKD) in advanced cases: a 8 -year-old boy with peritoneal dialysis and portal hypertension - left longitudinal view with an enlarged spleen, free abdominal dialysis fluid, and polycystic left kidney; b cholangiodysplasia in the same patient (later received successful combined kidneyliver transplantation); c 9-yearold girl with thickened periportal echogenicity as a sign of periportal fibrosis (transverse liver scan); d numerous macroscopic cysts in the kidney of the same girl (cysts are much larger than in neonates with ARPKD)
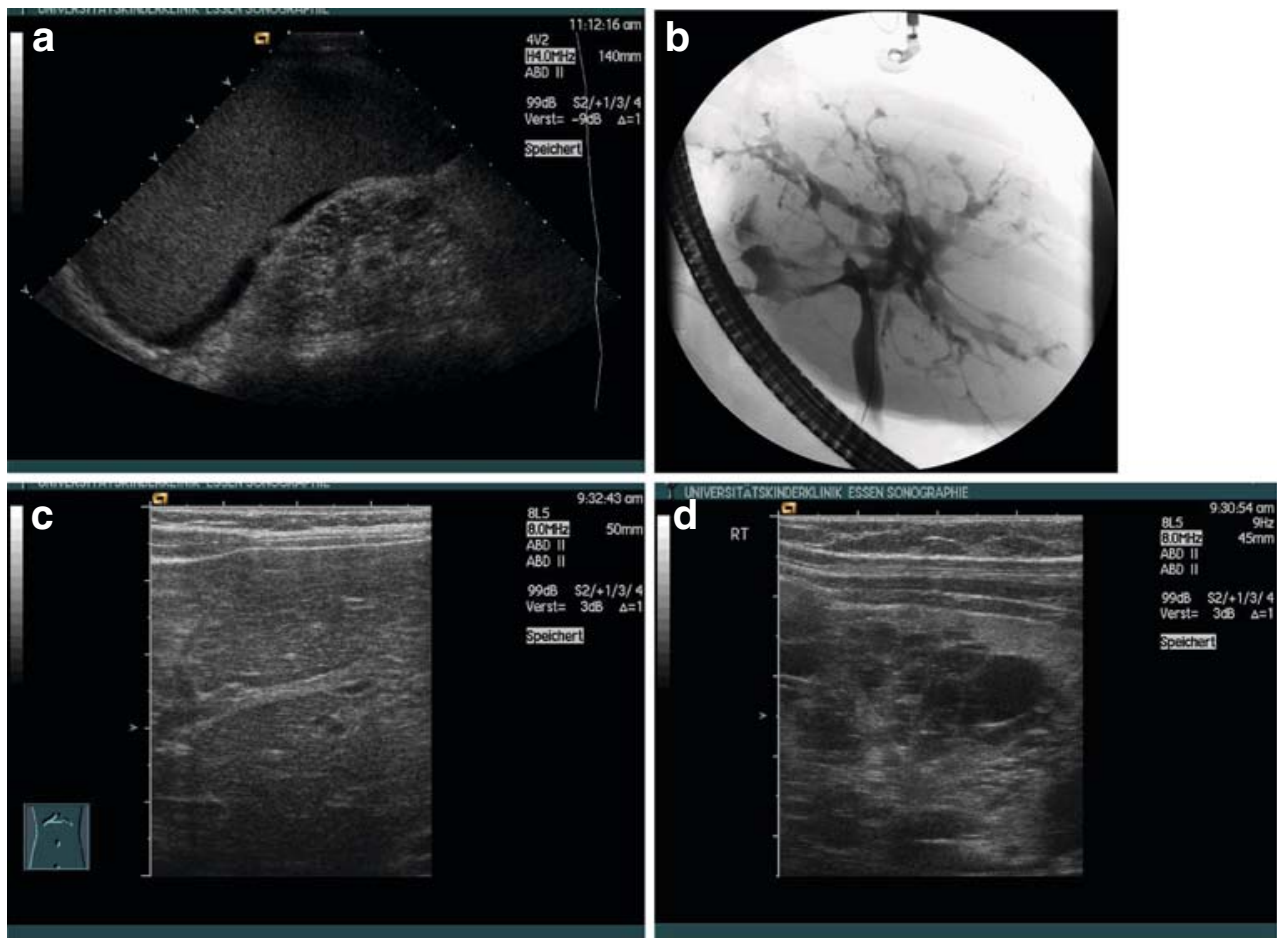

Renal dysplasia with cysts may occur sporadically or as part of a variety of syndromes. A recent textbook of pediatric nephrology lists 78 syndromes, many of which can be
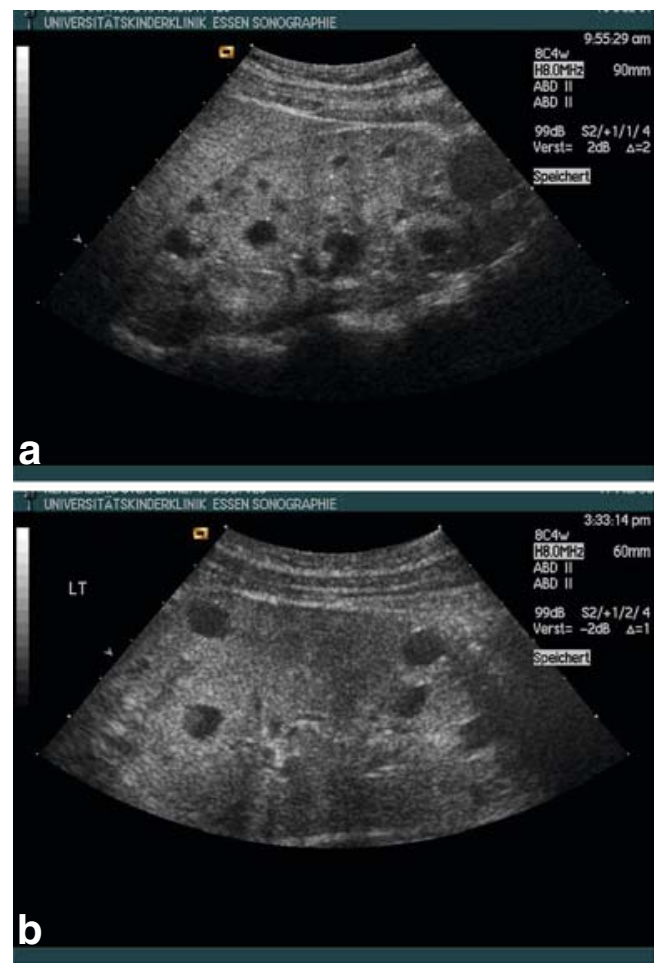

Fig. 7 Typical sonographic image of autosomal dominant polycystic kidney disease (ADPKD): a 10-year-old girl (father ADPKD); b 11year-old boy (father ADPKD) suspected after recognition of associated malformations [16]. Therefore, siblings of some affected children may need to be screened to exclude familial forms of renal dysplasia.

A typical sonographic feature of renal dysplasia is the lack of normal renal architecture, especially the differentiation between cortex and medulla. Echogenicity of a dysplastic kidney is usually enhanced, and cysts may be rare or numerous (Fig. 2a,b). Sonographic appearance does not necessarily correlate with renal function (Fig. 2c,d).

It should be stressed that a distinct phenotype cannot be expected regularly within the same syndrome, as shown in Fig. $3 \mathrm{a}-\mathrm{d}$. In these three siblings with a mutation of the hepatocyte nuclear factor (HNF)-1 $\beta$ encoded by the TCF2gene are shown. The phenotypic differences are obvious between right and left kidney in one patient (Fig. 3a,b) and between the siblings (Fig. 3c,d). HNF-1 $\beta$ mutations are found in up to $30 \%$ of unselected children with renal dysplasia and are frequently associated with maturity-onset diabetes of the young (MODY) type 5 and urogenital abnormalities [17].

Renal dysplasia with or without cysts in combination with urinary tract abnormalities is called CAKUT (congenital anomalies of kidney and urinary tract) [18-20]. In Fig. 4a,b, a dysplastic kidney in combination with urethral valves is shown. Figure 4c, d depicts two children with duplication of the ureter and ureterocele with dysplastic parenchyma of the upper renal pole, in Fig. 4c with and in Fig. 4d without cysts.

Autosomal recessive polycystic kidney disease (ARPKD). Autosomal recessive polycystic kidney disease (ARPKD) is 
Fig. 8 Autosomal dominant polycystic kidney disease (ADPKD) resembling autosomal recessive polycystic kidney disease (ARPKD): a 3-year-old boy with enlarged kidneys and small cysts; b father (38 years) of patient in a with multiple liver cysts and ADPKD; c 3week-old girl, oligohydramnios, hypertension, small cysts in large kidneys, with a calculated total kidney volume of 90 $100 \mathrm{ml}$ (normal value $<40 \mathrm{ml}$ according to [49] - mother ADPKD); $\mathbf{d}$ isolated spleen cyst in the same girl
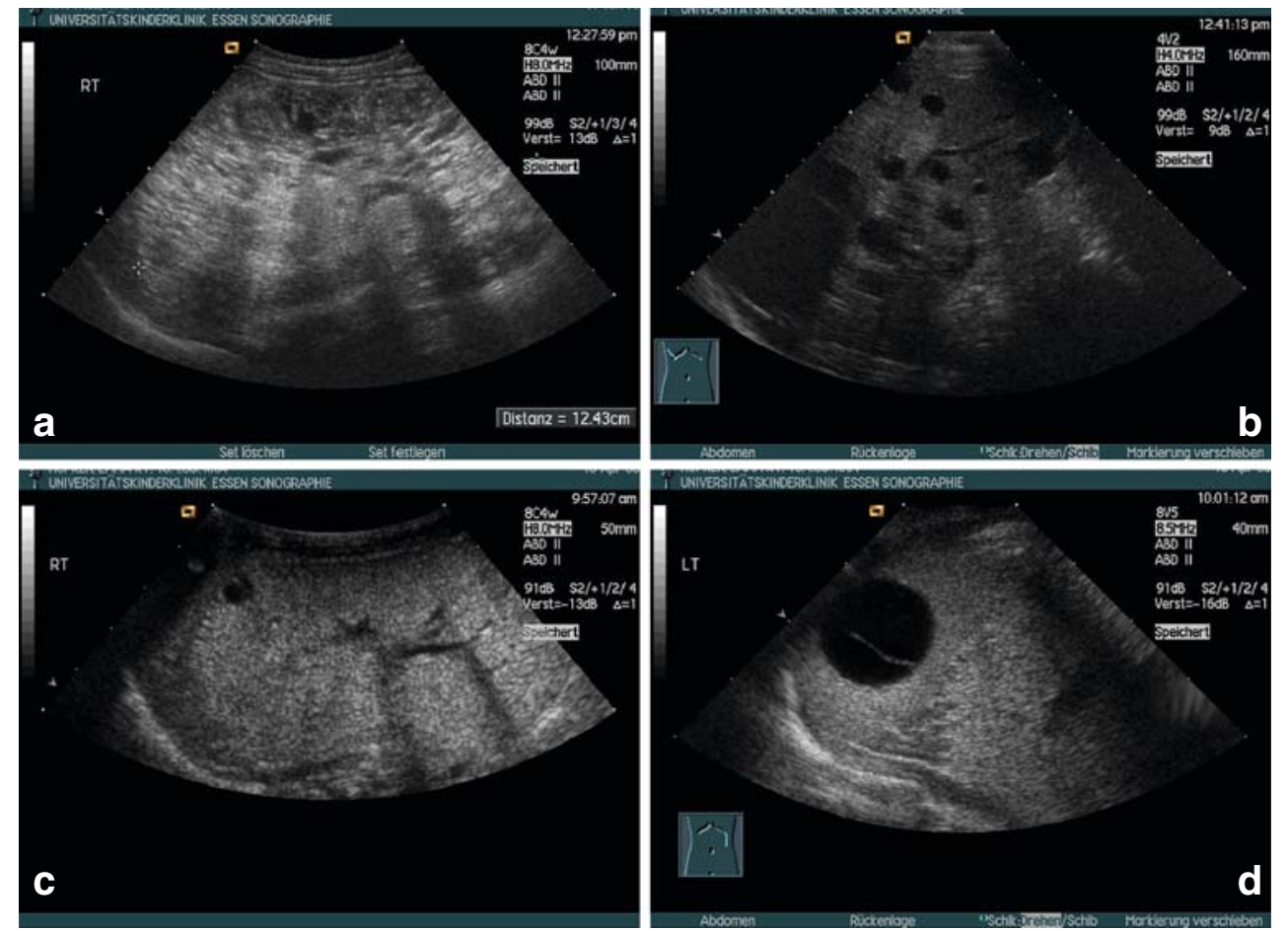

caused by mutations in the PKHDl-gene on chromosome 6 [21-23]. The clinical spectrum of ARPKD ranges from intrauterine death to early renal failure and hypertension or preserved renal function into adulthood [24]. In pre- and postnatal ultrasound, the kidneys appear grossly enlarged, with increased echogenicity and reduced corticomedullary differentiation [25, 26] (Fig. 5a-d). Renal cysts are confined to the collecting ducts and are usually so small that their size in infancy is close to the resolution capacity of ultrasound.

In advanced cases, renal cysts may become bigger, and progressive hepatic fibrosis will lead to portal hypertension with splenomegaly (Fig. 6a-d). Follow-up ultrasound is requested mainly to monitor hepatic fibrosis and portal hypertension.

Fig. 9 Juvenile nephronophthisis - sonographic appearance: normal or reduced kidney size, enhanced echogenicity of the renal cortex, and reduced corticomedullary differentiation (progressive with renal failure): a 13-year-old boy, creatinine $1.1 \mathrm{mg} / \mathrm{dl}$; b 16-year-old boy (brother of patient in a), creatinine $2.4 \mathrm{mg} / \mathrm{dl}$; c 16 -year-old girl, end-stage renal failure; d 9year-old boy, end-stage renal failure (cysts are a late sign)
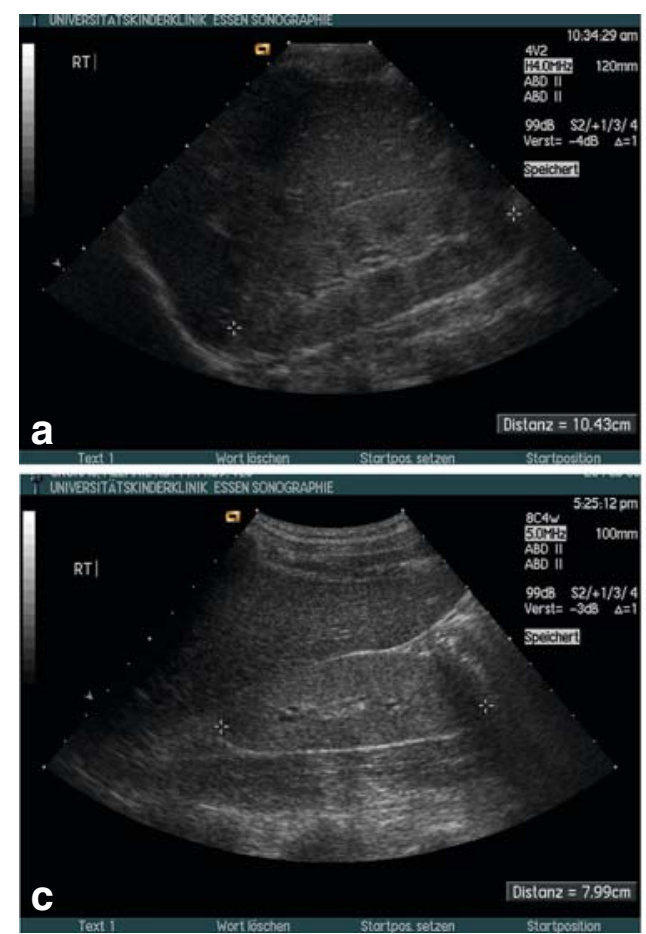
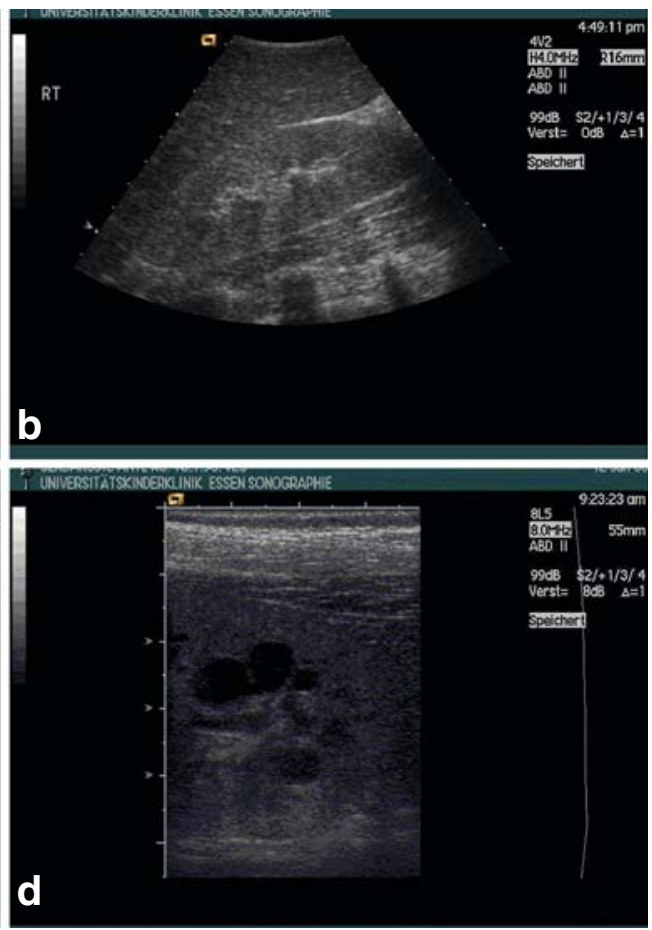
Fig. 10 Isolated renal cysts with normal renal function and absence of familiar cystic kidney disease: a 3-month-old boy, isolated cyst of the right kidney - family members normal; b 15 year-old girl, incidental finding of an isolated cyst of the left kidney; c 3-year-old boy, isolated large cyst (size $10 \times 9 \times 6 \mathrm{~cm}$, approximately $270 \mathrm{ml}$ ) ; d same boy as in $\mathbf{c}$ after surgery (* shows former cyst)
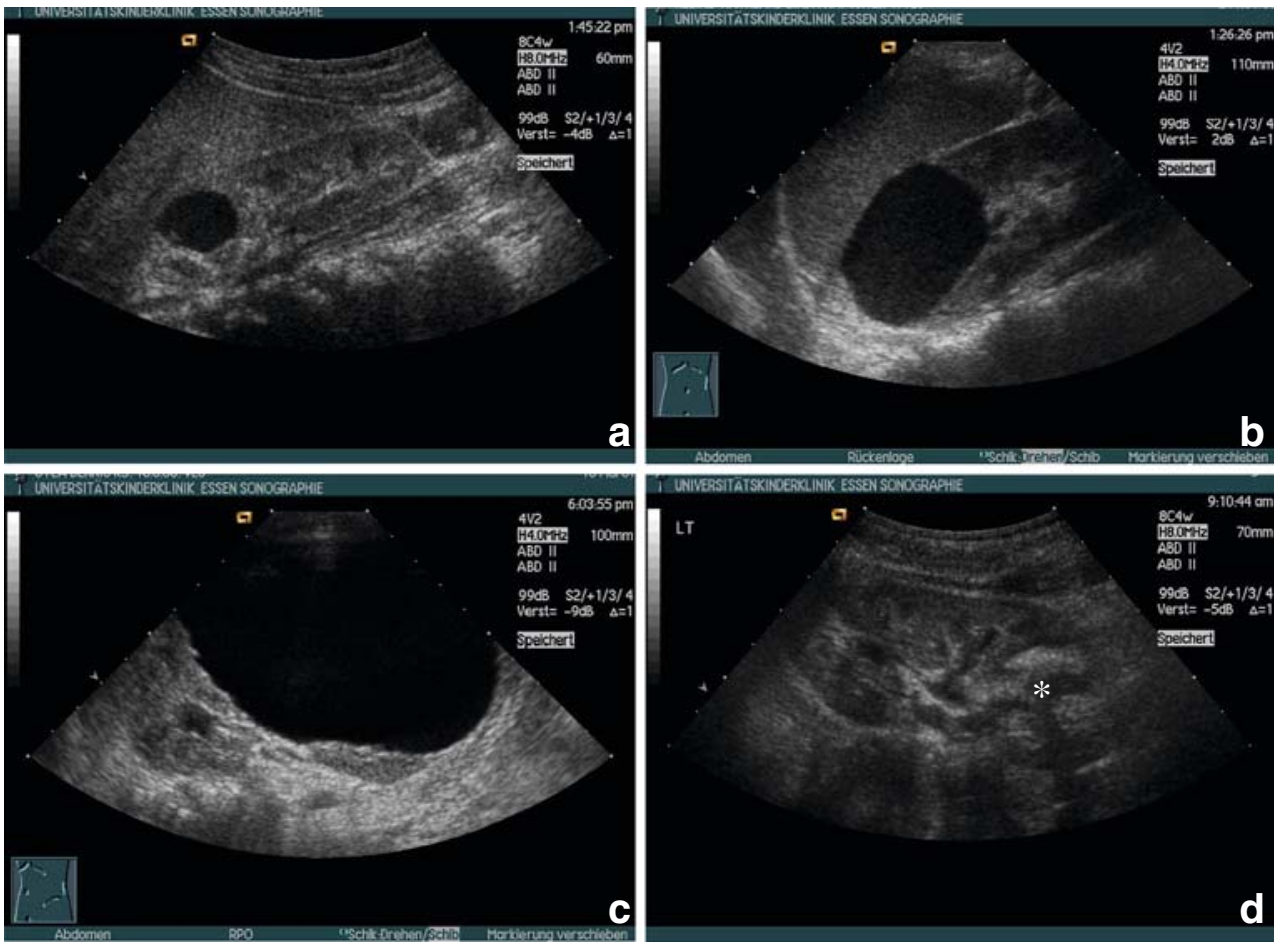

The variability of organ involvement in ARPKD is only partially understood [27] but is in part caused by the combination of mutations in the fibrocystin gene [28].

Autosomal dominant polycystic kidney disease (ADPKD). Autosomal dominant polycystic kidney disease (ADPKD) is the most common form of cystic disease, with a frequency of 1 in 800 live births and is caused by mutations in the PKD1 gene on chromosome 16 or the PKD2 gene on chromosome 4 [21]. With prenatal ultrasound, increased echogenicity of the renal cortex with increased corticomedullary differentiation is often found, but these findings are not specific [25]. In these cases, a family study is helpful, albeit most cases in childhood will be examined due to a positive family history. Clinical symptoms of ADPKD, as with hypertension and progressive enlargement

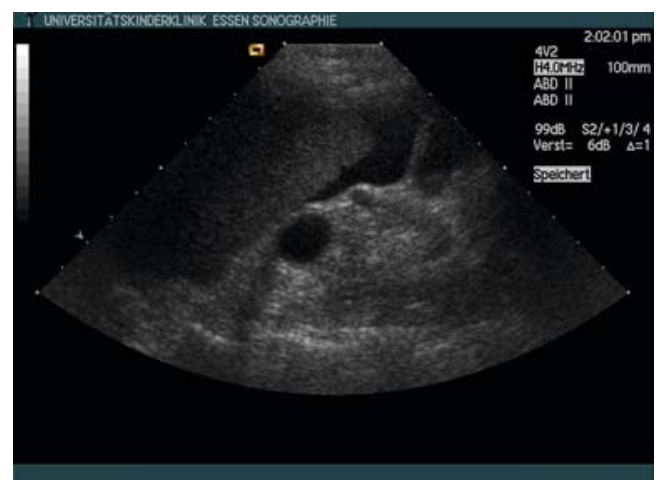

Fig. 11 Acquired renal cysts in end-stage renal failure: 16-year-old girl with Alport syndrome and peritoneal dialysis from the age of 2 years of the kidneys and renal failure, are mainly seen in adult patients and are more severe in PKD1-related cases [3]. In childhood, cyst formation can be detected in increasing number and size, which develop in an apparently normal kidney (Fig. 7a,b). However, cyst formation is a developing process, and a significant number of children with ADPKD will not show cysts before the second decade of life [29]. Renal failure is exclusively seen in individuals with severe kidney enlargement [30].

In some cases of ADPKD, tuberous sclerosis cannot be distinguished by kidney morphology [31]. This has been identified as a contiguous gene on chromosome 16 [32]. These cases have to be diagnosed with additional investigations on extrarenal manifestation, such as brain MRI, to detect cerebral hamartomas [5].

A special subgroup of patients with ADPKD may exhibit symptoms early in life [33], and it can be sonographically confused with ARPKD (Fig. 8a-d). Outcome in this subgroup of children with ADPKD seems to be better than in children with ARPKD [34]. Classification in dominant or recessive cystic kidney disease therefore always requires family studies.

Extrarenal manifestation of ADPKD may involve mitral valve ballooning, cerebral aneurysm, or cyst formation of other parenchymal organs, such as the liver, spleen (Fig. 8b, d), or pancreas [35]. As in ARPKD, the variability of ADPKD is only partially understood, with genetic, environmental, and hormonal modifiers identified so far [27]. In families with recessive or dominant forms of polycystic kidney disease, siblings should be screened, albeit prenatal ultrasound is not always conclusive [36]. 
Fig. 12 Cysts in renal tumors: a 9-year-old girl, small Wilms tumor with cysts; b 4-year-old boy, huge Wilms tumour with cysts of left kidney; c 2-weekold boy, mixed cystic and solid variant of a mesoblastic nephroma; d huge Wilms tumour with multiple cysts (transverse section); e, f 3-year-old boy, large kidney with multiple cysts - not a tumour but cystic dysplasia on histology; e transverse ultrasound, f magnetic resonance imaging
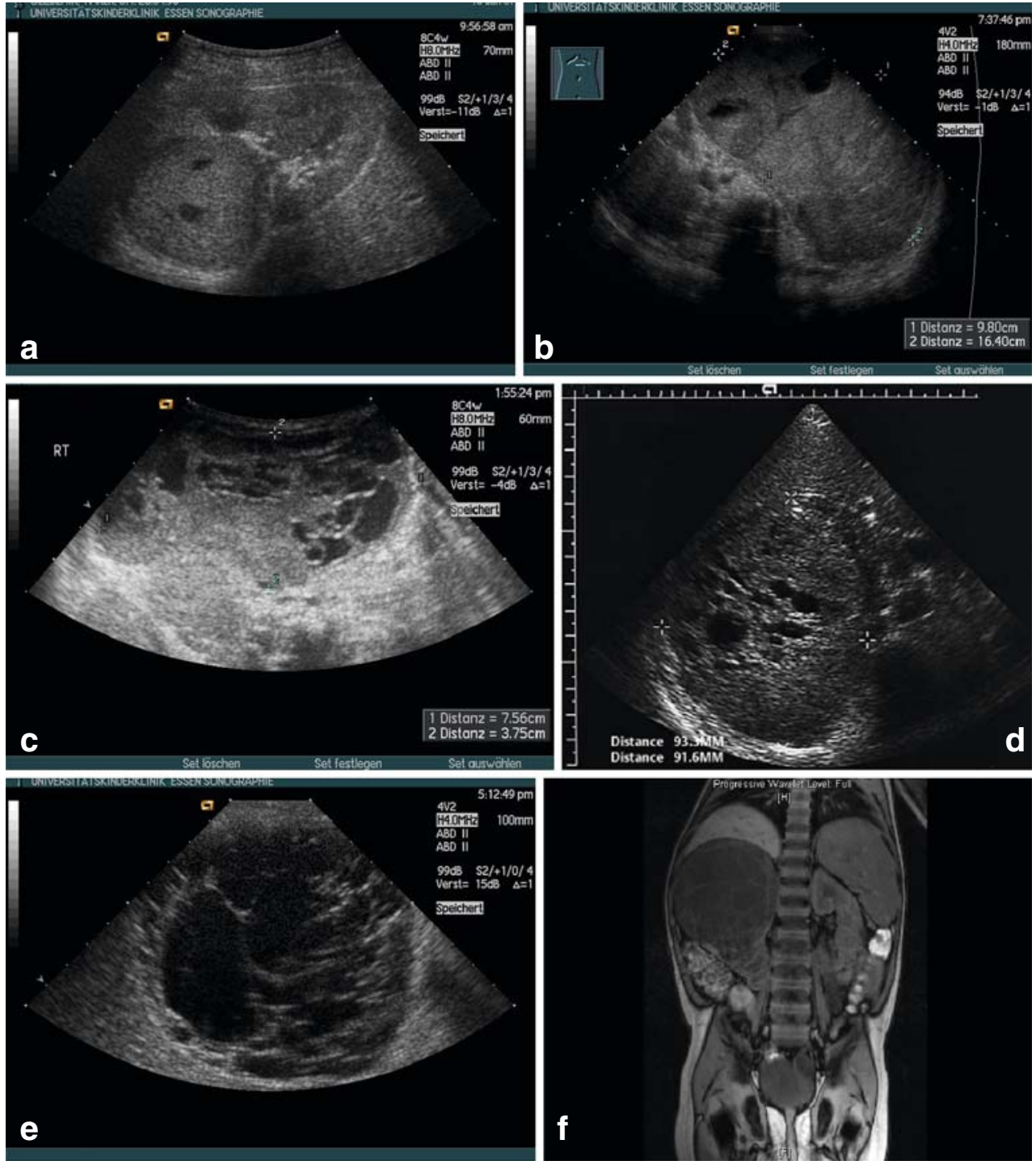

Nephronophthisis. The nephronophthisis complex consists of several heterogeneous autosomal recessive diseases in which gene products are linked with cilia or centrosomes [37]. The sonographic appearance of nephronophthisis at an early stage is nonspecific, with normal-shaped kidneys [38]. A reduction in corticomedullary differentiation can be detected early. Albeit nephronophthisis is a cystic kidney disease, cysts are seldom found at the initial stage of disease and mostly do not appear before end-stage renal failure is reached (Figs. 9a-d).

Diagnosis of nephronophthisis with sonography alone is ambiguous, and the final diagnosis is made in combination with the typical clinical signs and extrarenal manifestations and is confirmed by genetic testing [39].

Medullary cystic kidney disease (MCKD). MCKD is an autosomal dominant disorder with cystic dilation of the medullary part of the collecting ducts, which presents with gout and hyperuricemia in some cases and usually does not present before adulthood. So far, two loci on chromosomes 1 and 16 have been located. For the latter, mutations in the $U M O D$ gene have been described [40]. Ultrasound examination is nonspecific, similar to nephronophthisis.

Isolated cysts. Whereas benign cysts are found in up to $50 \%$ of the population older than 50 years, it is a rare finding in children [41]. Isolated cysts may be small or large (Fig. 10a-d). Multiple or bilateral cysts should always prompt suspicion to ADPKD and initiate family studies or follow-up examinations.

Acquired cystic kidney disease. Patients on dialysis often develop multiple cysts in their native kidney, even if the underlying disease is not cystic (Fig. 11). The pathogenesis of this cyst formation is not clearly understood, but the increased incidence of renal carcinomas in acquired cystic disease requires frequent and life-long monitoring of these kidneys [42, 43]. Regular follow-up and computed tomography (CT) or MRI in doubtful cases is advised, and 
removal of the nonfunctioning kidney should be considered in select cases [44].

Cysts within tumors. It is of obvious importance to emphasize that tumors might harbor some degree of cystic parenchyma with variable expression [45]. This includes multilocular cystic nephroma and cystic variants of clearcell sarcoma, renal cell carcinoma, nephroblastoma, or mesoblastic nephroma and should always be differentiated from benign lesions (Fig. 12a-f).

Miscellaneous. Cysts have been described in kidneys of patients with metabolic diseases such as glutaric acidemia type II or carnitine palmitoyltransferase type II deficiency or congenital disorders of glycosylation [46, 47].

\section{Summary}

Ultrasound is convenient to use through the entire pediatric age range, as it does not need sedation or preconditioning and does not expose the child to radiation. Modern equipment allows the diagnosis of nearly all variants of cystic kidney disease. Therefore, ultrasound is the very first diagnostic tool and will guide further diagnostic workup with additional imaging studies or genetic testing. However, knowledge of the phenotypic variety of cystic renal diseases [48] is essential to correlate the sonographic appearance within the clinical and genetic context. Training in ultrasound, or at least knowledge of sonographic interpretation, is part of the training in pediatric nephrology, and we advise every trainee to concentrate on this rewarding technique for the benefit of their patients.

Acknowledgment The authors thank R. Kolditz for excellent technical support and C. Bergmann for critically reviewing the manuscript. This work was supported by "Forschungsunterstützungskreis Kindernephrologie e.V.”, Essen, Germany.

\section{References}

1. Liapis H, Winyard P (2007) Cystic diseases and developmental kidney defects. In: Jennette JC, Olson JL, Schwartz MM, Silva FG (eds) Heptinstall's pathology of the kidney, 6th edn., Lippincott Williams \& Wilkins, Philadelphia, pp 1257-1306

2. Pohl M, Bhatnagar V, Mendoza SA, Nigam SK (2002) Toward an etiological classification of developmental disorders of the kidney and upper urinary tract. Kidney Int 61(1):10-19

3. Grantham JJ, Torres VE, Chapman AB, Guay-Woodford LM, Bae KT, King BF, Wetzel LH, Baumgarten DA, Kenney PJ, Harris PC, Klahr S, Bennett WM, Hirschman GN, Meyers CM, Zhang X, Zhu F, Miller JP, CRISP Investigators (2006) Volume progression in polycystic kidney disease. N Engl J Med 354(20):2122-2130

4. Perrone R (2006) Imaging progression in polycystic kidney disease. N Engl J Med 354(20):2181-2183

5. de Bruyn R, Gordon I (2000) Imaging in cystic renal disease. Arch Dis Child 83(5):401-407
6. Torres VE, Harris PC (2006) Mechanisms of disease: autosomal dominant and recessive polycystic kidney diseases. Nat Clin Pract Nephrol 2(1):40-55

7. Winyard P, Chitty L (2001) Dysplastic and polycystic kidneys: diagnosis, associations and management. Prenat Diagn 21(11):924 935

8. Aslam M, Watson AR, Trent \& Anglia MCDK Study Group (2006) Unilateral multicystic dysplastic kidney: long term outcomes. Arch Dis Child 91(10):820-823

9. Martin-Crespo R, Luque Mialdea R, Rodriguez Alarcon J, Pais E, Cebrian J, Fernandez A, Moreno L, Carrero C (2007) New concepts in the natural history of multicystic dysplastic kidney. Cir Pediatr 20(2):75-78

10. Kleiner B, Filly RA, Mack L, Callen PW (1986) Multicystic dysplastic kidney: observations of contralateral disease in the fetal population. Radiology 161(1):27-29

11. Atiyeh B, Husmann D, Baum M (1992) Contralateral renal abnormalities in multicystic-dysplastic kidney disease. J Pediatr 121(1):65-67

12. Kuwertz-Broeking E, Brinkmann OA, Von Lengerke HJ, Sciuk J, Fruend S, Bulla M, Harms E, Hertle L (2004) Unilateral multicystic dysplastic kidney: experience in children. BJU Int 93 (3):388-392

13. Moazin MS, Ahmed S, Fouda-Neel K (1997) Multicystic kidney in siblings. J Pediatr Surg 32(1):119-120

14. Kakkar N, Menon S, Radotra BD (2006) Histomorphology of renal dysplasia - an autopsy study. Fetal Pediatr Pathol 25(2):73-86

15. Warady BA, Chadha V (2007) Chronic kidney disease in children: the global perspective. Pediatr Nephrol 22(12):1999-2009

16. Limwongse C, Cassidy SB (2004) Syndromes and malformations of the urinary tract. In: Avner ED, Harmon WE, Niaudet P (eds) Pediatric nephrology, 5th edn. Lippincott Williams \& Wilkins, Philadelphia, pp 93-121

17. Ulinski T, Lescure S, Beaufils S, Guigonis V, Decramer S, Morin D, Clauin S, Deschênes G, Bouissou F, Bensman A, BellanéChantelot C (2006) Renal phenotypes related to hepatocyte factor$1 \mathrm{~b}$ (TCF2) mutations in a pediatric cohort. J Am Soc Nephrol 17 (2):497-503

18. Schedl A (2007) Renal abnormalities and their developmental origin. Nat Rev Genet 8(10):791-802

19. Nakanishi K, Yoshikawa N (2003) Genetic disorders of human congenital anomalies of the kidney and the urinary tract (CAKUT). Pediatr Int 45(5):610-616

20. Nagata M, Shibata S, Shu Y (2002) Pathogenesis of dysplastic kidney associated with urinary tract obstruction in utero. Nephrol Dial Transplant 17(Suppl 9):37-38

21. Wilson P (2004) Polycystic kidney disease. N Engl J Med 350 (2):151-164

22. Onuchic LF, Furu L, Nagasawa Y, Hou X, Eggermann T, Ren Z, Bergmann C, Senderek J, Esquivel E, Zeltner R, Rudnik-Schöneborn S, Mrug M, Sweeney W, Avner ED, Zerres K, Guay-Woodford LM, Somlo S, Germino GG (2002) PKHD1, the polycystic Kidney and Hepatic disease 1 Gene, encodes a novel large protein containing multiple immunoglobulin-like plexin-transcription-factor domains and parallel beta-helix 1 repeats. Am J Hum Genet 70(5):1305-1317

23. Ward CJ, Hogan MC, Rossetti S, Walker D, Sneddon T, Wang X, Kubly V, Cunningham JM, Bacallao R, Ishibashi M, Milliner DS, Torres VE, Harris PC (2002) The gene mutated in autosomal recessive polycystic kidney disease encodes a large, receptor-like protein. Nat Genet 30(3):259-269

24. Bergmann C, Senderek J, Windelen E, Küpper F, Middeldorf I, Schneider F, Dornia C, Rudnik-Schöneborn S, Konrad M, Schmitt CP, Seeman T, Neuhaus TJ, Vester U, Kirfel J, Büttner R, Zerres $\mathrm{K}$, APN (2005) Clinical consequences of PKHD1 mutations in 164 patients with autosomal-recessive polycystic kidney disease (ARPKD). Kidney Int 67(3):829-848 
25. Avni FE, Garel L, Cassart M, Massez A, Eurin D, Didier F, Hall M, Teele RL (2006) Perinatal assessment of hereditary cystic renal diseases: the contribution of sonography. Pediatr Radiol 36 (5):405-414

26. Avni FE, Guissard G, Hall M, Janssen F, DeMaertelaer V, Rypens F (2002) Hereditary polycystic kidney diseases in children: changing sonographic patterns through childhood. Pediatr Radiol 32(3):169-174

27. Rossetti S, Harris PC (2007) Genotype-phenotype correlations in autosomal dominant and autosomal recessive polycystic kidney disease. J Am Soc Nephrol 18(5):1374-1380

28. Bergmann C, Senderek J, Sedlacek B, Pegiazoglou I, Puglia P, Eggermann T, Rudnik-Schöneborn S, Furu L, Onuchic LF, De Baca M, Germino GG, Guay-Woodford L, Somlo S, Moser M, Buttner R, Zerres K (2003) Spectrum of mutations in the gene for autosomal recessive polycystic kidney disease (ARPKD/PKHD1). J Am Soc Nephrol 14(1):76-89

29. Gabow PA Kimberling WJ, Strain JD, Manco-Johnson ML, Johnson AM (1997) Utility of ultrasonography in the diagnosis of autosomal dominant polycystic kidney disease in children. $\mathrm{J}$ Am Soc Nephrol 8(1):105-110

30. Nicolau C, Torra R, Badenas C, Pérez L, Olivier JA, Darnell A, Brú C (2000) Sonographic pattern of recessive polycystic kidney disease in young adults. Differences from the dominant for. Nephrol Dial Transplant 15(9):1373-1378

31. Webb DW, Super M, Normand CS, Osborne JP (1993) Tuberous sclerosis and polycystic kidney disease. BMJ 306(6887):12581259

32. Brook-Carter PT, Peral B, Ward CJ, Thompson P, Hughes J, Maheshwar MM, Nellist M, Gamble V, Harris PC, Sampson JR (1994) Deletion of the TSC2 and PKD1 genes associated with severe infantile polycystic kidney disease - a contiguous gene syndrome. Nat Genet 8(4):328-332

33. Tee JB, Acott PD, McLellan DH, Crocker JF (2004) Phenotypic heterogeneity in pediatric autosomal dominant polycystic kidney disease at first presentation: a single-center, 20 year review. Am J Kidney Dis 43(2):296-303

34. Boyer O, Gagnadoux MF, Guest G, Biebuyck N, Charbit M, Salomon R, Niaudet P (2007) Prognosis of autosomal dominant polycystic kidney disease diagnosed in utero or at birth. Pediatr Nephrol 22(3):380-388

35. Torres VE, Grantham JJ (2004) Cystic diseases of the kidney. In: BM Brenner (ed) Brenner and Rector's The kidney, 8th edn, Saunders, Philadelphia, pp 1428-1462
36. Roume J, Ville Y (2004) Prenatal diagnosis of genetic renal diseases: breaking the code. Ultrasound Obstet Gynecol 24(1):1018

37. Hildebrandt F, Otto E (2005) Cilia and centrosomes: a unifying pathogenic concept for cystic kidney disease? Nat Rev Genet 6 (12):928-940

38. Chuang YF, Tsai TC (1998) Sonographic findings in familial juvenile nephronophthisis-medullary cystic disease complex. J Clin Ultrasound 26(4):203-206

39. Komatsuda A, Wakui H (2005) Nephronophthisis: diagnostic difficulties and recent advances in molecular genetic diagnostics. Clin Exp Nephrol 9(4):340-342

40. Hart TC, Gorry MC, Hart PS, Woodard AS, Shihabi Z, Sandhu J, Shirts B, Xu L, Zhu H, Barmada MM, Bleyer AJ (2002) Mutations of UMOD gene are responsible for medullary cystic kidney disease 2 and familial juvenile hyperuricaemic nephropathy. J Med Genet 39(12):882-892

41. Mir S, Rapola J, Koskimies U (1983) Renal cysts in pediatric autopsy material. Nephron 33(3):189-195

42. Schwarz A, Vatandaslar S, Merkel S, Haller H (2007) Renal cell carcinoma in transplant recipients with acquired cystic kidney disease. Clin J Am Soc Nephrol 2(4):750-756

43. Noronha IL, Ritz E, Waldherr R, Stein G, Fassbinder W (1989) Renal cell carcinoma in dialysis patients with acquired renal cysts. Nephrol Dial Transplant 4(9):763-769

44. Mattoo TK, Greifer I, Geva P, Spitzer A (1997) Acquired renal cystic disease in children and young adults on maintenance dialysis. Pediatr Nephrol 11(4):447-450

45. Riccabona M (2003) Imaging of renal tumours in infancy and childhood. Eur Radiol 13(Suppl 4):L116-L129

46. Distelmaier F, Vogel M, Spiekerkötter U, Gempel K, Klee D, Braunstein S, Groneck HP, Mayatepek E, Wendel U, Schwahn B (2007) Cystic renal dysplasia as a leading sign of inherited metabolic disease. Pediatr Nephrol 22(12):2119-2124

47. Strom EH, Stromme P, Westvik J, Pedersen SJ (1993) Renal cysts in carbohydrate-deficient glycoprotein syndrome. Pediatr Nephrol 7(3):253-255

48. Bisceglia M, Galliani CA, Senger C, Stallone C, Sessa A (2006) Renal cystic diseases: a review. Adv Anat Pathol 13(1):26-56

49. Schmidt IM, Main KM, Damgaard IN, Mau C, Haavisto AM, Chellakooty M, Boisen KA, Petersen JH, Scheike T, Olgaard K (2004) Kidney growth in 717 healthy children aged 018 months: a longitudinal cohort study. Pediatr Nephrol 19 (9):992-1003 